\title{
"Operação Oswaldo Cruz"
}

FRANCISCO DA ROCHA LAGÖA

Ministro da Saúde

"Vivemos uma hora em que, na decidida busca do desenvolvimento, se impõe a união de todos os esforços, iluminados por um entusiasmo comum. Impõe-se a ação de todos, na dedicação de cada um, traçando-se roteiros seguros para uma caminhada produtiva, enfrentando-se, com bravura e confiança, problemas secularmente esquecidos, abrindo-se novos horizontes para a realização de confortadoras esperanças. Nesse impulso abençoado de progresso, chegamos aos limites da Amazônia, cuidando de al ver, afinal, mais que o espetáculo misterioso das selvas, o "drama do homem no seu desesperado esfôrço de sobrevivência". Cerrou-se o velário sôbre as magnificências do sonho, tudo se fazendo convite ou desafio para realizações que levem a uma legítima integração nacional. E é isso o que vimos fazendo, num labor ciclópico em que a preocupaçăo central é desenvolver sem destruir, aproveitar sem sacrificar, utilizar sem consumir. E' vasto o programa, não valendo, contudo, proclamar o que se pretende fazer, pois o que conta é mostrar o que já se fêz e o que se está fazendo. Isto o que objetiva o Ministério da Saúde, presente às atividades que Ihe cabem, na área especifica de suas atribuições.

Nos limites dos recursos de que dispõe, multiplicados pelo entusiasmo dos que nêle e a êle servem, já plantou o Ministério da Saúde seus postos de ação para a defesa sanitária da região, organizando a "Operação OSWALDO CRUZ", bem definida em seus propósitos, dentro do lema que norteou a vida daquele que fol o maior sanitarista do Brasil: "Não esmorecer para não desmerecer". $\mathrm{Em}$ pouco tempo, já muito alcançou a Operação, à qual não tem faltado apoio e colaboração de outras unidades governamentais $e$, também, a valiosa participação dos universitários do País. Sob êsses auspicios, não há dúvida: a vitória é certa." (*)

Inte A grande missão do Ministério da Saúde no Plano de se gração é a preservação da saúde do homem que vai fixar- Amazônia, defendendo-o dos possiveis males existentes de um ds Mensagem enviada aos trabalhadores da Transamazônica, por ocasiăo da ida
grupos da "Operaçăo OSWALDO CRUZ" 
na região e evitando que a mesma seja contaminada por doenças a ela estranhas e introduzidas por quem vai habitá-la.

Assim, a grande perspectiva do programa de integração nacional na Amazônia é a fixação do homem na região misteriosa tantas vêzes louvada por poetas e prosadores na majestade de sua flora e na singularidade de sua fauna. Para isso, há que pensar, antes do mais, na terra que está sendo desbravada e no homem que está desbravando-a, donde ressalta 0 fator saúde, que se mantendo íntegro não permitirá que se repitam insucessos verificados em outras áreas e em outros tempos. Dêsse modo impõe-se, entre as medidas preliminares da arrancada que se verifica, a eliminação das doenças que possam existir entre os membros da comunidade em marcha, bem como a sua proteção no sentido de não ser vítima de outros males por acaso existentes na região.

No caso específico da Transamazônica, em que estão sendo encaminhadas, para zonas ainda mal conhecidas ou desconhecidas em parte, levas ponderáveis da mais variada população - trabalhadores que estão abrindo a rodovia, colonos e respectivas famílias - surge como primeira medida sanitária - contrôle da saúde daqueles que estão se deslocando para a estranha terra, a fim de não transportarem, para a mesma, outras doenças.

Sabe-se, com segurança, da inexistência, nas terras a serem colonizadas, de várias moléstias, freqüentes em outras, como no Nordeste, por exemplo. Sendo assim, impõe-se preservar aquelas de males que destas possam ser levados. Por outro lado, existe na região amazônica uma série de doenças próprias, algumas já devidamente pesquisadas e outras ainda pouco conhecidas até hoje, por falta de possibilidades de estudo, mas que vêm sendo investigadas. Provàvelmente alguns males eclodirão tão pronto haja condições favoráveis, como 0 contato do homem com os animais silvestres da região, que são portadores naturais das mesmas, mas serão identificados. Devem assim, ser particularmente consideradas as zoonoses que ocorrem na floresta amazônica, algumas já classificadas pelo Instituto Evandro Chagas, de Belém do Pará, e grupadas em quatro categorias:

doenças a vírus;

doenças parasitárias;

doenças bacterianas $\mathrm{e}$

doenças produzidas por fungos. 
Resulta, do que aí fica dito em linhas gerais, a importância que terão, necessàriamente, as medidas preventivas que estão sendo tomadas durante a execução do programa de integração da Amazônia pela abertura da Transamazônica.

É assim que a vacinação antiamarílica é aplicada em todos os individuos que se deslocam ou têm contatos, ainda que esporádicos, com as frentes de trabalho, sabida a possibilidade da presença daquele mal contra o qual a vacina protege decididamente.

Estão merecendo cuidados especiais as turmas destacadas para a derrubada das matas e para a construção de acampamentos e para tais tarefas é preferencialmente indicado pessoal já adaptado ao ambiente, isto é, habitantes da área rural da bacia amazônica com provável contato anterior com a floresta, pois é de presumir que boa percentagem dessa gente já tenha adquirido imunidade contra as doenças consideradas.

Os terrenos destinados aos acampamentos são totalmente limpos, de forma que nenhuma construção fica a menos de cem (100) metros da floresta, tomadas naturalmente medidas que impeçam a criação de indesejáveis desertos, com derrubadas extensas.

As casas estão sendo teladas para evitar a entrada de anofelinos transmissores da malária e tôda a população é submetida, rigorosamente, a tratamento profilático semanal contra a doença.

Os acampamentos vêm sendo dotados de banheiros e lavanderias, para que se evite o contato da população com as correntes de água natural, sendo indispensável, também, um sistema de água potável e de remoção adequada de dejetos.

Infere-se do exposto que duas medidas essenciais se faZem necessárias à preservação da saúde daqueles que vão se do na região: a seleção prévia, para impedir o carreamento os doenças às terras ainda virgens delas e prevenção contra de males que lhes são próprios, além de permanente estado cidas para pronta identificação das doenças pouco conheou ainda desconhecidas que possam surgir.

A fim de que o Govêrno possa levar a bom têrmo o seu programa de integração nacional da Amazônia, com ampla e traura proteção da saúde daqueles que vão executá-la, nesse Ministér que vem marcando a nossa época, está presente o istério da Saúde com a "Operação OSWALDO CRUZ", 
na qual se conjugam os esforços dos vários órgãos especializados desta Secretaria de Estado - Fundação Serviços de Saúde Pública (FSESP) - Superintendência das Campanhas de Saúde Pública (SUCAM) e Fundação Instituto Oswaldo Cruz (FIOCruz) - ajudados pelo entusiasmo cívico dos universitários de medicina dos Estados, com responsabilidade nos pontos de ação, o que lhes serve de ótima fonte de ensinamentos e, também, possivelmente, de oportunidade para ulterior fixação no local.

A ação conjugada é desenvolvida pela Fundação Serviços de Saúde Pública, através das unidades de medicina integrada, algumas já existentes e outras a serem implantadas na região.

A Superintendência das Campanhas faz-se presente pela ação preventiva desenvolvida pelos vários órgãos que a constituem.

Por sua vez, à Fundação Instituto Oswaldo Cruz está reservada a tarefa dos estudos e pesquisas sôbre as doenças existentes na região, especialmente através do seu órgão regional, que é o Instituto Evandro Chagas. Assim, também, a produção de vacinas necessárias está a seu encargo.

A participação dos universitários visa a entregar a cada Unidade da Federação a responsabilidade de atuar em uma das frentes de trabalho, engajando-se as suas universidades nos trabalhos de medicina preventiva e curativa e de pesquisas, ora em desenvolvimento.

A hora que estamos vivendo é de servir com sabedoria e humildade. E que nisso ponha cada um o melhor de si mesmo, fazendo do trabalho a oração de tôdas as manhãs, pois é no labor honesto e persistente que o homem se coloca mais perto de Deus. $\mathrm{E}$ com êsse pensamento que, instituída a "Operação OSWALDO CRUZ", que leva o imortal lema: "NÃO ESMORECER PARA NÃO DESMERECER", que o Ministério da Saúde presta a sua colaboração ao cumprimento do programa de integração nacional da Amazônia, certos todos que "ninguém mais segura êste País" na marcha gloriosa para seus luminosos destinos.

$\mathrm{Na}$ missão que vem sendo empreendida o Ministério da Saúde já procedeu à vacinação de todo o pessoal existente na área, seja como trabalhadores, seja como colonizadores. Extenso programa de medicina preventiva vem sendo desenvolvido pela Superintendência das Campanhas de Saúde Pública 
(SUCAM), que mantém nas frentes de trabalho equipes de borrifação com inseticidas e de microscopistas. Por sua vez, a Fundação Serviços de Saúde Pública (FSESP) mantém unidades sanitárias integradas em Altamira, Marabá, Santarém e Itaituba, além das subunidades estabelecidas junto às agrovilas que vão se implantando ao longo das rodovias, nas proximidades dessas cidades.

Por outro lado, finalmente, sob todos os aspectos, a ajuda prestada pelos universitários, conforme já foi exposto, vem se mostrando relevante.

PROJETO PARA ASSISTENNCIA MÉDICO-SANITÁRIA EM APOIO A CONSTRUÇÃO DA RODOVIA TRANSAMAZONNICA E A FIXAÇÃO DOS NÚCLEOS DE COLONIZAÇÃO

\section{Da Transamazônica - Traçado da Estrada}

A Transamazônica tem origem como prolongamento natural na selva, nas BR-230 e BR-232, que partindo de João Pessoa e Recife, respectivamente se confluem na cidade de Picos. Dessa cidade até a Belém-Brasília, a rodovia passa por Floriano, São Raimundo das Mangabeiras e Carolina. Da Belém-Brasília a Transamazônica parte para oeste seguindo a rota Pôrto Franco, Marabá, Tucuruí, Altamira, Itaituba, Jacareacanga, Santo Antônio de Prainha e Humaitá. Em Humaitá articula-se com a rêde rodoviária da Amazônia em fase de implantação, articulando-se, também, com a estrada Lábrea - Bôca do Acre-Rio Branco.

\section{Municípios Diretamente Envolvidos}

De Pôrto Franco a Humaitá, ou seja, ao longo do traçado da Transamazônica, trecho cuja construção vai ter início, destacam-se por sua importância os seguintes municípios: Pôrto Franco, Marabá, Jatobal, Tucuruí, Altamira, Itaituba, Jacareacanga, Santo Antônio de Prainha e Humaitá.

Em Itaituba a estrada cruza com a Santarém-Cuiabá, salientando-se o Município de Santarém onde esta se origina.

3. Informações Sumárias Sôbre os Municípios

\subsection{Pôrto Franco:}

aproximado no Estado do Maranhão, com uma população de $\mathrm{km}^{2}$. A madamente 17.000 habitantes, com uma área de 4.400 por A densidade demográfica é de 4 (quatro) habitantes por $\mathrm{km}^{2}$. O Município tem ligações previstas com tôdas as ca- 
pitais do nordeste. Está em construção, na sede municipal, um sistema de abastecimento de água. No que se refere à saúde, procede-se no momento a um levantamento dos recursos.

\subsection{Marabá:}

Situado no Estado do Pará, com uma população de 29.232 habitantes, com uma área de $49.763 \mathrm{~km}^{2}$ e densidade de 0.46 por $\mathrm{km}^{2}$. A sede municipal conta com um abastecimento de água administrado mediante convênio da F/SESP com a Prefeitura Municipal.

Funciona uma unidade mista com 25 leitos, capacitada a prestar assistência médico-cirúrgica em regime de ambulatório e em regime de hospitalização, além das atividades de saúde pública. É administrada pela F/SESP.

\subsection{Jatobal:}

$\mathrm{Na}$ falta de informação, está sendo procedido um levantamento dos recursos.

\subsection{Tucuruí:}

Situado no Estado do Pará, com uma população de 7.032 habitantes, área de $5.124 \mathrm{~km}^{2}$ e densidade demográfica de 1.37. Em elaboração um projeto de sistema de água para a sede municipal. Procede-se ao levantamento dos recursos médico-sanitários.

\subsection{Altamira:}

Situado no Estado do Pará, com uma população de 13.301 habitantes, área de $153.862 \mathrm{~km}^{2}$ e densidade demográfica de $0.07 \mathrm{~km}^{2}$. Nesse município já se acham instalados vários grupos de colonos, dedicados à agricultura. Altamira está ligada por estrada de rodagem à cidade de Tubarão no rio Xingu, por onde se escoa a produção da área. $\mathrm{Na}$ sede municipal existe um abastecimento de água, administrado mediante convênio F/SESP com a Prefeitura Municipal. Tem uma unidade sanitária operada pela referida Fundação. Possui ainda um hospital da Prelazia de Xingu, com 24 leitos em funcionamento precário.

\subsection{Itaituba:}

Situado no Estado do Pará, com uma população de 10.132 habitantes, área de $26.058 \mathrm{~km}^{2}$ e densidade demográfica de 4,29 habitantes por $\mathrm{km}^{2}$. A sede municipal conta com um abastecimento de água. Procede-se ao levantamento dos recursos médico-sanitários. 


\subsection{Jacareacanga e Santo Antônio de Prainha:}

Situados no Estado do Pará, ao longo do trecho ItaitubaHumaitá. São localidades que se destacam como pontos de apoio para a construção da estrada. Procede-se ao levantamento dos recursos médico-sanitários.

\subsection{Humaitá:}

Situado no Estado do Amazonas. É ponto terminal da Transamazônica, com uma população de 18.261 habitantes, área de $34.431 \mathrm{~km}^{2}$ e densidade demográfica de 0.53 habitantes por $\mathrm{km}^{2}$. Possui um sistema de abastecimento de água administrado mediante convênio entre a F/SESP e a Prefeitura Municipal. Dispõe de um hospital da Prelazia dos Salesianos, funcionando de modo precário.

\subsection{Santarém:}

Situado no Estado do Pará. Ponto inicial da estrada para Cuiabá. Conta com uma população de 121.653 habitantes; área de $26.058 \mathrm{~km}^{2}$ e densidade de 4,29. Dispõe de um abastecimento de água, administrado em convênio com a F/SESP e Prefeitura Municipal. Conta com uma unidade mista com capacidade para 50 leitos, administrada pela F/SESP. Esta unidade presta não sòmente assistência médico-cirúrgica, como desenvolve atividades de saúde pública.

\section{Bases do Sistema da Assistência Médico-Sanitária a ser prestada}

A Rodovia Transamazônica vai propiciar a implantação e desenvolvimento da colonização de tôda a área. Os numerosos acampamentos que as emprêsas contratantes construirão ao longo do seu percurso, dotados de infra-estrutura de apoio, Permanecerão como núcleos pioneiros de colonização.

Assim sendo, o que preocupa no ponto de vista médicoSanitário não é apenas o problema do homem recrutado no nordeste para a construção da estrada. É também o de suas Para e dos núcleos de população que serão instalados. assegurar a prestação de serviços de saúde em caráter per4.1.

\subsection{Assistência ao Trabalhador}

Ceder da responsabilidade das emprêsas contratantes: proao trabalhome inicial de saúde para seleção dos candidatos trabalho; tomar as medidas preventivas indispensáveis e 
prestar a assistência médico-sanitária necessária a assegurar a proteção e recuperação da saúde dos trabalhadores, destacando-se as emergências decorrentes do trabalho e outras.

Essa assistência será feita através de unidades móveis ou transportáveis, dotadas de leitos, laboratórios, raios X portátil, centro cirúrgico e gabinete dentário que serão deslocados de acôrdo com o progresso da estrada. É ainda da responsabilidade das emprêsas proporcionar assistência médico-cirúrgica em instituições mais diferenciadas, as mais acessiveis a partir do local de trabalho, removendo os pacientes até essas unidades de recuperação, utilizando os meios mais rápidos de transporte.

Finalmente, cabe-lhes construir habitações higiênicas, dotadas de privadas e dos requisitos indispensáveis à proteção contra os vetores e transmissores comuns à região. Os acampamentos serão levantados em áreas distando pelo menos 100 metros da orla da floresta. A água receberá o tratamento indicado de acôrdo com as circunstâncias locais.

Ao Ministério da Saúde, que já entregou às emprêsas construtoras normas gerais para execução dessas atividades, competirá realizar supervisão permanente dos mesmos para assegurar a continuidade da assistência médico-sanitária às frentes de trabalho.

\subsection{Unidades Básicas de Saúde}

Em face ao exposto no que se refere à fixação dos núcleos de colonização e o desenvolvimento das áreas atravessadas pela estrada, é necessário organizar uma rêde de unidades básicas de saúde, serviços permanentes, capacitadas a prestar tôda assistência médico-sanitária indispensável às populações locais, à população flutuante e aos próprios trabalhadores.

Êsses serviços serão instalados nas seguintes localidades: Pôrto Franco, Marabá, Jatobal, Tucuruí, Altamira, Itaituba, Jacareacanga, Santo Antônio do Prainha, Humaitá e Santarém, podendo estender-se à Imperatriz, Monte Alegre, Pôrto Velho, Lábrea e Bôca do Acre, onde existem unidades locais de saúde.

Em Pôrto Franco, Marabá, Altamira, Itaituba, Humaitá e Santarém funcionarão unidades mistas com capacidade de 50 leitos. São unidades regionais. Jatobal, Tucuruí, Jacareacanga e Santo Antônio de Prainha, e outras localidades com intervalo de $150 \mathrm{~km}$, serão dotadas de unidades semelhantes, porém, com capacidade de 25 leitos. São unidades zonais. 
Essas unidades serão instaladas de modo a permitir a execução de medidas preventivas, assim como a de todos os cuidados destinados à proteção e recuperação da saúde.

Nas cidades de Marabá e Santarém, as unidades serão ampliadas e ajustadas às necessidades do programa. A unidade de Altamira será acrescida das instalações necessárias à prestação de serviços médico-cirúrgicos em regime de hospitalização. Nas demais cidades serão instaladas novas unidades.

Serão utilizadas unidades pré-fabricadas com área útil variável de conformidade com as atividades que irão desenvolver.

Concluídos os estudos em andamento poderá ser programada a instalação de unidades proporcionais às exigências encontradas, no interior dos municípios. Serão unidades locais.

Um sistema de unidades móveis será organizado para atender as populações fixadas ao longo das vias fluviais que se articulam com a Transamazônica. Essas unidades serão o prolongamento das atividades das unidades fixas onde têm base.

Nas cidades já mencionadas que servem de apoio à construção da Transamazônica e à colonização da região, o Ministério da Saúde tomará as medidas necessárias para a construção ou ampliação de sistemas de abastecimento de água.

5. Construção, Operação e Manutenção das Unidades

5.1. Estimativa do custo de construção (ou aquisição) e de instalação de unidades

O custo da aquisição ou da construção e de instalação de Cada unidade regional (Unidade de 50 leitos) é estimado em $\mathrm{Cr} \$ 5.000 .000,00$. O das unidades zonais (Unidades de 25 leitos) é estimado em Cr\$3.750.000,00.

A despesa com aquisição de cada unidade móvel varia entre $\mathrm{Cr} \$ 3.000 .000,00$ e $\mathrm{Cr} \$ 5.000 .000,00$, conforme sua instalação e capacidade.

Nessas condições a estimativa de despesa com a construção, instalação e ampliação das unidades programadas alcança a importância total de $\mathrm{Cr} \$ 132.000 .000,00$, sendo:

- $\operatorname{Cr} \$ 30.000 .000,00$, para 6 unidades regionais (Pôrto Franco, Marabá, Altamira, Itaituba, Humaitá e Santarém);

- Cr\$ 45.000.000,00, para 12 unidades zonais (Jatobal, Tucuruí, Jacareacanga, Santo Antônio da Prainha, e outras em localidades com $150 \mathrm{~km}$ de intervalo);

- $\mathrm{Cr} \$ 27.000 .000 .00$, para 12 unidades locais, distribuídas no interior dos municípios; 
- Cr\$15.000.000,00, para aquisição de 3 unidades fluviais, completamente equipadas para assistência médico-hospitalar;

- Cr\$15.000.000,00, para aquisição de 6 unidades móveis menores.

\subsection{Estimativa do Custo Operacional}

O custo de operação de cada unidade regional (50 leitos) é estimado em $\mathrm{Cr} \$ 1.000 .000,00$, dos quais $60 \%$ com pessoal e $40 \%$ com material e outras despesas (6 unidades - Cr\$ 6.000.000,00).

O custo de operação de cada unidade zonal (25 leitos) é estimado em Cr\$5.000.000,00, distribuídos na mesma proporção anteriormente referida (12 unidades $-\ldots \ldots \ldots \ldots \ldots$ Cr\$ 6.000.000,00).

O custo de operação de cada unidade local é estimado em Cr\$ 250.000,00, distribuídos nas mesmas proporções anteriormente referidas (12 unidades - Cr\$3.000.000,00).

As unidades fluviais e as demais unidades móveis têm uma despesa estimada em cêrca de Cr\$3.000.000,00.

Dêsse modo, o custo operacional se eleva a $\mathrm{Cr} \$$ $18.000 .000,00$, totalizando os gastos previstos com assistência médica programada a importância de Cr\$150.000.000,00.

\section{Abastecimento de Agua}

O custo da construção de abastecimento de água nessa área é presentemente estimado em $\mathrm{Cr} \$ 100,00$ por habitante. Para melhorar as condições sanitárias das comunidades ainda não beneficiadas cuja população é calculada em 50.000 habitantes, serão necessários Cr\$ 5.000.000,00.

\section{Outras Atividades}

O Ministério da Saúde intensificará os estudos, pesquisas e investigações epidemiológicas que vem realizando na região. Prosseguirá no combate às endemias, principalmente à malária e à febre amarela, de modo a aumentar a proteção das comunidades urbanas e das populações do interior.

\section{Considerações Finais}

Em se tratando de um estudo preliminar com base em informações ainda incompletas, o projeto poderá sofrer reajustamentos em sua estratégia. Do mesmo modo o custo estimado para a construção, instalação e operação dos serviços poderá sofrer alterações.

Finalmente, considere-se que as necessidades em recursos humanos e seu treinamento exigirão despesas adicionais. 